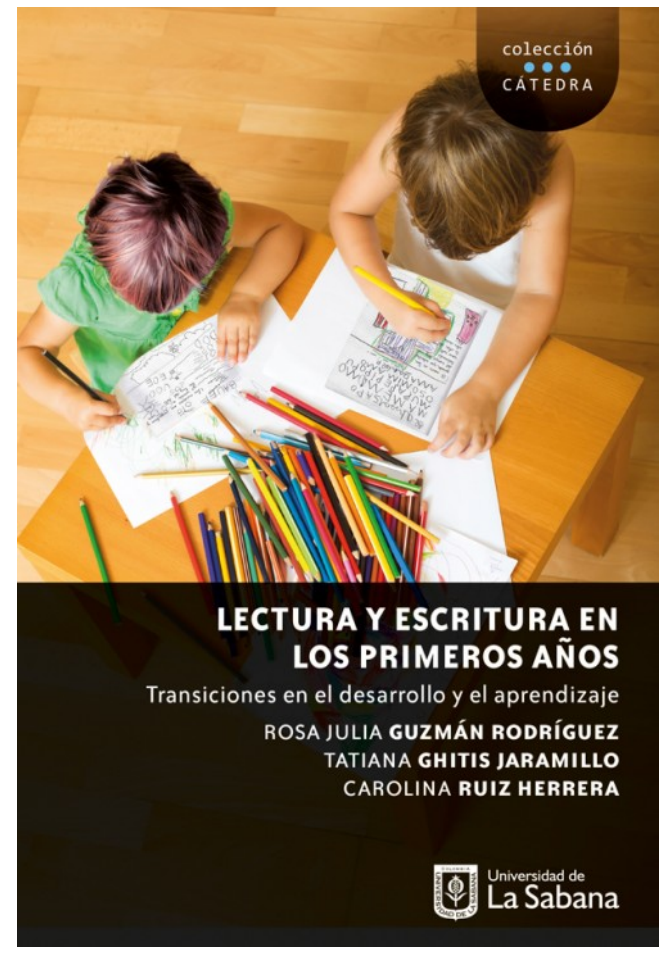

\title{
LECTURA Y ESCRITURA EN LOS PRIMEROS AÑOS TRANSICIONES EN EL DESARROLLO Y EL APRENDIZAJE
}

Por: Rosa Julia Guzmán, Tatiana Ghitis Jaramillo, Carolina Ruiz Herrera Formato: Impreso

ISBN: 978-958-12-0474-8

Facultad: Educación

Colección: Cátedra \# 16

DOI: https://doi.org/10.5294/978-958-12-0474-8

Idioma: Español

Precio en dólares: USD $\$ 20,00$

Número de páginas: 176

Palabras clave: Aprendizaje, Educación primaria, Escritura, Lectura elemental

\section{$\$ 55.000$}

\section{Reseña del Producto}

Este libro es producto de la reflexión sobre muchos años de prácticas d e enseñanza, que se articulan con resultados d e investigaciones adelantadas tanto en el aula como fuera $\mathrm{d}$ e ella, por profesores e investigadores nacionales e internacionales en la enseñanza y el aprendizaje de la lectura y la escritura. De igual manera, responde a la necesidad de enseñar la lectura y la escritura desde el ciclo inicial en una perspectiva pedagógica, que articula los conocimientos que los niños construyen en interacción con el medio en que se desenvuelven, con los procesos de enseñanza escolar, en busca de continuidad entre ellos.

\section{Información Adicional}

Peso: $1 \mathrm{~kg}$

Tamaño: $17 \times 24 \times 2 \mathrm{~cm}$

Sku: 9789581204748

Código topografico: 372.42

\section{Tabla de contenido}

\section{PRESENTACIÓN}

INTRODUCCIÓN

1. BASES TEÓRICAS DE LOS PROCESOS DE LECTURA Y ESCRITURA

El proceso de escritura

Construcción de la lengua escrita

Continuación del proceso de enseñanza de la escritura para promover nuevos avances

Relación entre los aprendizajes incidentales que se dan en el medio social y la alfabetización inicial

Alfabetismo emergente

El proceso de la lectura

La influencia del contexto en el aprendizaje de la lectura 
La relación del pensamiento con la lectura y la escritura

Las rutinas de pensamiento

2. ANÁLISIS DE LAS PRÁCTICAS DE ENSEÑANZA 69 MÉTODOS TRADICIONALES DE ENSEÑANZA DE LA LECTURA Y LA ESCRITURA

Enseñanza de la lectura y la escritura en el aula

Consideraciones antropológicas

Consideraciones del desarrollo infantil

Consideraciones pedagógicas

Consideraciones didácticas

3. BASES PEDAGÓGICAS PARA LA ALFABETIZACIÓN INICIAL

Implicaciones pedagógicas en la enseñanza de la lectura y la escritura y reflexión sobre el uso de los métodos

Enseñanza de la lectura y escritura

Aprendizaje de la lectura y escritura

El pensamiento en los procesos de lectura y escritura

Evaluación en los procesos de lectura y escritura

Estrategias de trabajo para la enseñanza de la lectura y escritura

Los proyectos de aula

Las secuencias didácticas

Las unidades de comprensión

¿Cómo puede producirse un analfabeta funcional en la institución escolar?

4. DIDÁCTICA DE LA ALFABETIZACIÓN INICIAL

Procesos articuladores en las transiciones

Relación alfabetismo emergente-alfabetización inicial

Estructuras organizadoras de articulación de la enseñanza

Generación de estrategias en el aula

Cómo se pueden promover avances en la escritura

Ejercicios para desarrollar la lectura en el aula

BIBLIOGRAFÍA 